\title{
Cobertura verde: um estudo experimental para análise do comportamento térmico utilizando plataformas de testes
}

\author{
Rafael Perussi $^{(a)}$, Rafael Gotardi Brússolo ${ }^{(b)}$ \\ ${ }^{(a)}$ Programa de Pós-Graduação em Ciências da Engenharia Ambiental/Universidade de São Paulo, Escola de \\ Engenharia de São Carlos, rafaelperussi @ gmail.com \\ (b) Programa de Pós-Graduação em Ciências da Engenharia Ambiental/Universidade de São Paulo, Escola de \\ Engenharia de São Carlos, rgbrussolo@usp.br
}

Eixo: Climatologia em diferentes níveis escalares: mudanças e variabilidade.

\begin{abstract}
Resumo
O objetivo desta pesquisa é analisar o comportamento térmico de um sistema extensivo de cobertura verde através de um experimento composto por duas plataformas de testes, sendo uma coberta com grama-amendoim e a outra mantida sem cobertura vegetal. Foram monitoradas as temperaturas dos níveis superior e inferior do substrato e as temperaturas externas, abaixo das plataformas, juntamente com os dados climáticos, registrados por uma estação meteorológica automática. As análises do comportamento térmico foram realizadas a partir das abordagens da Climatologia Dinâmica. A cobertura verde apresentou melhor desempenho térmico em relação à cobertura controle devido ao maior atraso térmico entre as superfícies e menor amplitude térmica nas superfícies. Concluiu-se que, para um dia quente e seco, a vegetação influencia os processos de troca de calor no perfil do substrato pelo bloqueio da radiação solar incidente, permitindo que a temperatura se manifeste com maior atraso na superfície inferior.
\end{abstract}

Palavras chave: Coberturas verdes, Comportamento térmico, Climatologia dinâmica.

\section{Introdução}

As edificações são construídas principalmente para promover segurança e proporcionar um ambiente mais adequado às atividades humanas, e podem ser consideradas a melhor forma de termorregulação, ou seja, a função destas construções é proteger os indivíduos das intempéries a que estão sujeitos, mantendo em seu interior uma proteção contra os rigores do clima. Neste sentido, o principal requisito às edificações é promover o menor estresse térmico aos usuários (OKE, 1987).

As coberturas verdes são sistemas construtivos utilizados na cobertura de edificações com o objetivo de amortecimento térmico ou redução da velocidade de escoamento das águas pluviais (SUSCA et al, 2011), e consiste na sobreposição de diversas camadas sobre uma superfície estrutural, que de modo geral incluem impermeabilização, sistema de drenagem, substrato e plantas. As coberturas verdes com com espessura de 0,02 a 0,20 m são denominadas pela literatura como "coberturas verdes extensivas". Já as 
coberturas com espessura de substrato acima de $0,20 \mathrm{~m}$ são denominadas "coberturas verdes intensivas". (DURHMAN et al., 2007).

As plantas utilizadas nas coberturas verdes devem ser preferencialmente nativas, adaptadas ao clima local, de crescimento rasteiro, com maior área foliar, raízes curtas, demandem menor quantidade de rega e poda e apresentem elevada resistência a estresses climáticos. As espécies do gênero Arachis estão entre as plantas recomendadas para uso em coberturas verdes no trabalho conduzido por Yok e Sia (2008). Comumente denominada de amendoim forrageiro, a Arachis pintoi é uma planta originária do Brasil, que apresenta boa adaptação em áreas de alta precipitação, com solos de moderada fertilidade e com restrições à seca e encharcamento demasiado e encontra-se difundida nas zonas tropicais e subtropicais do Brasil e do mundo (BAPTISTA, 2007).

A diferença entre as coberturas vegetadas e as sem vegetação é qualitativa e quantitativa. O processo de transferência de calor é totalmente diferente. A radiação solar, a temperatura externa e a umidade relativa apresentam valores mais baixos assim que passam a camada da vegetação sobre a cobertura. As plantas, para as suas funções biológicas como a fotossíntese, transpiração e evaporação, absorvem uma quantidade significativa de radiação solar. A radiação solar restante alterada em termos de carga térmica influencia o clima interno à medida que passa através da vegetação e dos elementos do telhado (NIACHOU et al., 2001).

A radiação solar é o fator que mais influencia nos processos de trocas térmicas, devido a sua forte incidência direta nas superfícies dos fechamentos e, também, devido às radiações provenientes do entorno. O fluxo de calor sempre ocorre a partir de uma região de maior temperatura para uma região de baixa temperatura e atua no sentido de equalizar as diferenças de temperatura (COSTA, 1982; SERRA, 2002; YOUNG; FREEDMAN, 2008)

Condições climáticas consideradas satisfatórias, segundo os parâmetros bioclimáticos de conforto ambiental, são muito raras, no entanto é possível conceber espaços mais coerentes às necessidades físicas e psicológicas pressupostas pelas zonas de conforto, com baixo custo de manutenção, e reduzindo o condicionamento térmico artificial. Neste sentido, fica evidente a importância do conhecimento das condições climáticas, pois podem inferir em padrões de ocupação territorial, na concepção de projetos arquitetônicos, e até mesmo auxiliar em processos de tomada de decisão em diversos aspectos ambientais (FREITAS, 2005; CUNHA; VECCHIA, 2007). O Brasil possui quase que a totalidade de seu território sujeita a intensa insolação durante a maior parte do ano. Por este motivo, a cobertura deveria ser o elemento com maior proteção térmica. 
A possibilidade de adotar a abordagem dinâmica do clima oferece, em um curto intervalo de tempo, subsídios para o entendimento das condições climáticas e possíveis repercussões sobre o ambiente construído, com relação à conservação de energia e ao comportamento e desempenho térmicos de edifícios (SEIXAS, 2015).

$\mathrm{Na}$ abordagem dinâmica o que diferencia os episódios são a intensidade e duração de cada massa de ar sobre o local. Para isso a coleta dos dados de radiação solar global e dos elementos do clima é de fundamental importância para análise dos processos atmosféricos, que acontecem de forma sucessiva, encadeada e inter-relacionada, configurando o ritmo climático, não se esquecendo de considerar os fatores geográficos de modificação. Após a análise do episódio representativo do fato climático, pode-se eleger um dia representativo das ocorrências climáticas, para visibilidade do objeto de estudo.

Portanto, a utilização correta da Climatologia Dinâmica depende da visualização dos encadeamentos de tipos de tempo atmosférico, a partir de respostas locais colhidas por meio das variações diárias e horárias dos elementos do clima (medições em superfície, por meio de estações e postos meteorológicos) e das imagens fornecidas por satélites meteorológicos. Entretanto, o simples acesso a esse banco de dados não é suficiente. Faz-se necessária a correta interpretação dos valores para o real entendimento dos processos atmosféricos (VECCHIA, 1997).

Neste contexto, o presente estudo propôs mensurar e avaliar o comportamento térmico de um sistema extensivo de cobertura verde e, também, comparar o comportamento térmico com uma cobertura controle sem vegetação construídos sobre plataformas de teste no período de transição primavera-verão em uma região de clima tropical de altitude no Estado de São Paulo visando sua aplicação em edificações.

\section{Procedimentos metodológicos}

O experimento foi composto por duas plataformas de testes construídas de forma a reproduzir um sistema de cobertura verde extensiva nas quais foram instalados conjuntos de sensores conectados a um sistema de aquisição de dados. O sistema permitiu registrar a evolução temporal dos parâmetros necessários ao estudo do comportamento térmico. Uma plataforma recebeu o plantio de vegetação, denominada "Plataforma Verde", e a outra foi mantida sem vegetação, denominada "Plataforma Controle", a qual simula o comportamento térmico de um solo exposto. Foram monitoradas as temperaturas do nível superior e inferior do substrato e também as temperaturas externas abaixo da base das plataformas.

As análises do comportamento térmico foram realizadas a partir das abordagens espacial e temporal da Climatologia Dinâmica, que permite visualizar fenômenos de caráter temporal mais exíguo, como a identificação do ritmo climático expresso pelo regime de chuvas, pelos períodos de elevada secura do ar, 
ou mesmo pela variação dos valores da pressão barométrica ao longo da penetração de frentes frias, acompanhadas pela alteração da velocidade e da direção predominantes dos ventos (CUNHA; VECCHIA, 2007), possibilitando a identificação de episódios representativos do fato climático e suas repercussões sobre os valores das temperaturas obtidas das plataformas de teste através da elaboração e análise de gráficos.

O trabalho foi conduzido no Centro de Recursos Hídricos e Estudos Ambientas - CRHEA da Escola de Engenharia de São Carlos, Universidade de São Paulo - EESC-USP. O CRHEA está localizado às margens da Represa do Lobo no município de Itirapina-SP, região central do Estado de São Paulo, entre as

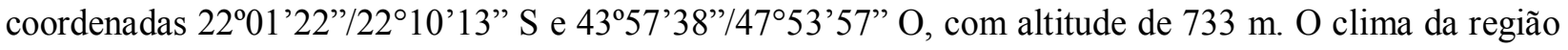
é quente com inverno seco do tipo Cwa de acordo com a classificação clássica de Köppen-Geiger (PEEL, 2007). Sob a ótica dinâmica do clima, a região se caracteriza pela passagem de frentes frias ao longo de todo o ano. Segundo Monteiro (1973) a região de São Carlos possui clima controlado por massas equatoriais e tropicais, caracterizando-se por climas tropicais alternadamente secos e úmidos. No período seco, entre os meses de abril e setembro, a frequência de chuva diminui consideravelmente e se constitui na área de inverno nitidamente mais seco do Estado de São Paulo, quando predominam sobre a região as massas de ar Tropical Continental (mTc), Tropical Atlântica (mTa) e Polar Atlântica (mPa), apresentando baixa precipitação, pouca nebulosidade, baixa umidade relativa e temperaturas médias menores que as dos períodos chuvosos.

\section{Contrução das plataformas e aquisição dos dados}

A estrutura das plataformas consiste em uma caixa construída com compensado de madeira com dimensões de 2,20m x 2,20m de base com laterais de $0,15 \mathrm{~m}$ de altura. A estrutura foi fixada em barras de aço galvanizado e suspensa por duas traves de madeira a uma altura de 1,00 $\mathrm{m}$ do solo. Outras quatro chapas de madeira foram fixadas lateralmente, abaixo da base, formando uma cavidade para funcionar como quebra-vento. Foi adotada uma inclinação de 5\% para a estrutura afim de se obter uma drenagem lenta e otimizar o tempo de retenção da água, de forma a tornar mais uniforme a distribuição da umidade no substrato.

As plataformas foram impermeabilizadas com uma membrana plástica e para a drenagem foi utilizada um geotêxtil não-tecido aderido a uma geomanta tridimensional flexível formada por filamentos plásticos, que permitem a filtragem e escoamento da água. As plataformas foram preenchidas com substrato elaborado com uma mistura de substrato vegetal comercial com solo retirado do local, de modo a se obter uma espessura de 0,10 m. Para compor a cobertura da plataforma vegetada foi selecionada a espécie Arachis pintoi (grama-amendoim) (Figura 1). 


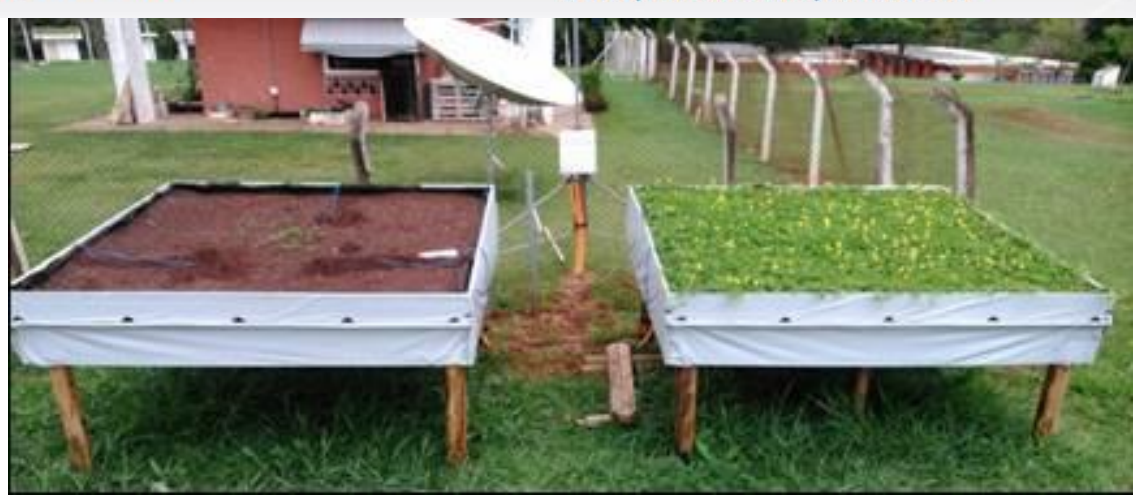

Figura 1: Plataformas de testes. Fonte: Os autores.

Para se obter as medições de temperatura foram instalados nas plataformas de testes 14 termopares tipo T (cobre-constantan) a um datalogger CR10X (Campbell Scientific Inc.), com totalização dos registros a cada 30 minutos. Cada plataforma recebeu um conjunto de 7 sensores, sendo 3 no nível superior do substrato, 3 inferiores, no nível mais profundo do substrato e 1 externo, abaixo da base da plataforma. Em ambas as plataformas os sensores superiores foram fixados abaixo de uma camada de $0,5 \mathrm{~cm}$ de substrato, os sensores inferiores fixados a $0,10 \mathrm{~m}$ de profundidade e os sensores externos fixados na superfície da base externa das plataformas em um pequeno orifício e protegido com pasta térmica.

Os sensores superiores da Plataforma Verde foram denominados como Verde Superior (VS), os inferiores denominados como Verde Inferior (VI) e os externos denominados como Verde Externo (V Ext). Na Plataforma Controle, os sensores superiores foram denominados como Controle Superior (CS), os inferiores denominados como Controle Inferior (CI) e os externos denominados como Controle Externo (C Ext). Para o posicionamento dos sensores, a área da plataforma foi dividida em três terços longitudinalmente e transversalmente encontrando-se um quadrado central onde foi traçado um triângulo em cujas extremidades foram fixados os sensores. Os sensores externos foram posicionados no centro geométrico da base das plataformas. As Figuras 2A, 2B e 2C mostram o posicionamento dos sensores nas plataformas.

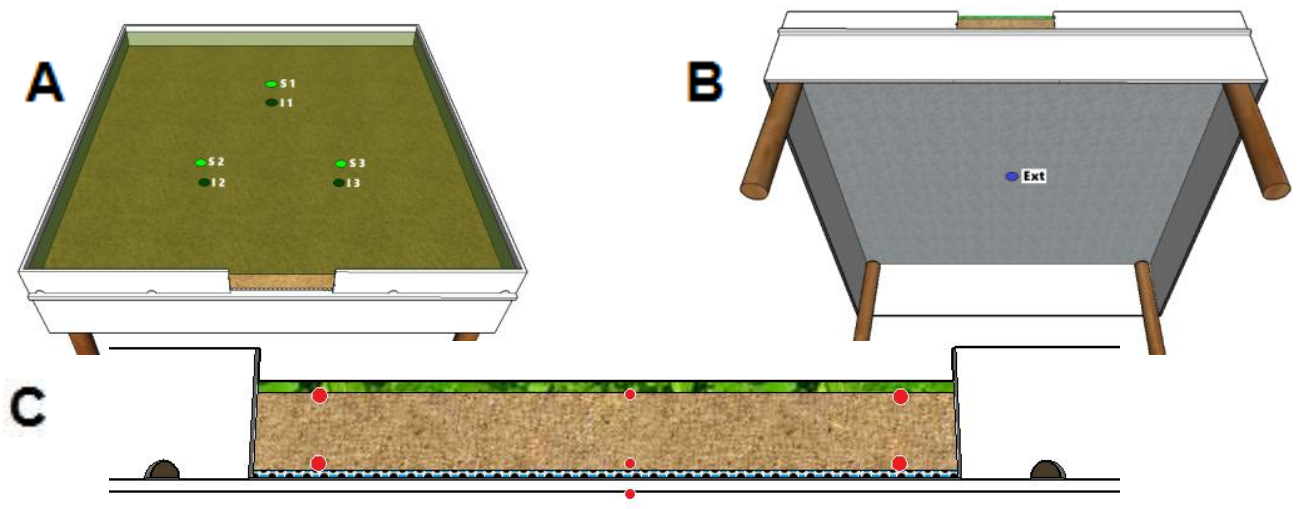


Figura 2: (A) Representação com a indicação do posicionamento dos sensores superiores e inferiores no substrato; (B) do sensor externo nas plataformas e (C) corte mostrando o posicionamento dos sensores. Fonte: Os autores.

Para a análise do comportamento térmico foi utilizada a média aritmética dos valores registrados simultaneamente pelos 3 sensores de cada superfície do substrato (superior e inferior) de ambas as plataformas, denominadas como Temperatura Média Verde Superior ( $\theta$ VS), Temperatura Média Verde Inferior ( $\theta \mathrm{VI})$, Temperatura Média Controle Superior ( $\theta \mathrm{CS})$, Temperatura Média Controle Inferior $(\theta \mathrm{CI})$, permitindo-se assim comparar os valores entre os dois níveis do substrato e superfícies externas ao longo do período de análise. As temperaturas externas foram denominadas Temperatura Verde Externa ( $\theta \mathrm{V}$ Ext) e Temperatura Controle Externa $(\theta \mathrm{C}$ Ext).

\section{Análise episódica dos tipos de tempo}

Os dados das variáveis climáticas foram coletados pela estação meteorológica automática do CRHEA, composta por um conjunto de sensores específicos conectados a um datalogger CR1000 (Campbell Scientific Inc) programado para obter medições dos sensores a cada 30 segundos, com totalização a cada 30 minutos. Foram utilizados registros de radiação solar global, temperatura máxima, mínima e umidade relativa do ar, pressão atmosférica, precipitação e velocidade e direção do vento.

O regime climático local foi analisado na forma de episódios representativos, de acordo com a adaptação de Vecchia (1997) da definição de Tipos de Tempo de Monteiro (1969), onde são considerados os dados meteorológicos tomados em superfície junto às propriedades das massas de ar que atuam sobre um determinado local, permitindo que seja determinada a fase mais apropriada à realização de experimentos quando da necessidade de uma análise climática voltada ao estudo do comportamento térmico de um sistema de cobertura e, no caso do presente trabalho, da sua reação frente ao calor.

Utilizou-se também como referência as Normais Climatológicas 1961 - 1990 (1992) computadas pelo Instituto Nacional de Meteorologia (INMET), revisadas e ampliadas em 2009 e que abrange 414 estações meteorológicas de superfície em operação durante anos do período entre 01/01/1961 a 31/12/1990, cobrindo um conjunto de 26 parâmetros meteorológicos.

\section{Resultados}

\subsection{Análise do período de coleta}

O episódio climático representativo selecionado para análise foi registrado entre os dias julianos 288 a 294 (15 a 21/10/2015), dias em que a região esteve sob o domínio de uma massa de ar de característica quente e seca e de onde foram extraídos os dias típicos experimentais. Para a identificação das massas atuantes foram avaliados os dados das principais variáveis climáticas do período e com confirmação da massa 
XVII Simpósio Brasileiro de Geografia Fisica Aplicada

I Congresso Nacional de Geografia Física
OS DESAFIOS DA GEOGRAFIA FÍSICA NA FRONTEIRA DO CONHECIMENTO

Instituto de Geociências - Unicamp

Campinas - SP

28 de Junho à 02 de Julho de 2017

atuante no Estado de São Paulo, identificada por meio de imagens do satélite GOES-13 (Geostationary Operational Environmental Satellite), fornecidos pelo Centro de Previsão de Tempo e Estudos Climáticos (CEPTEC-INPE) e das cartas sinóticas fornecidas pela Marinha do Brasil, que permitiram a visualização do movimento das massas sobre a região Sudeste do país, onde as áreas brancas indicam a presença de nuvens (Figura 3).

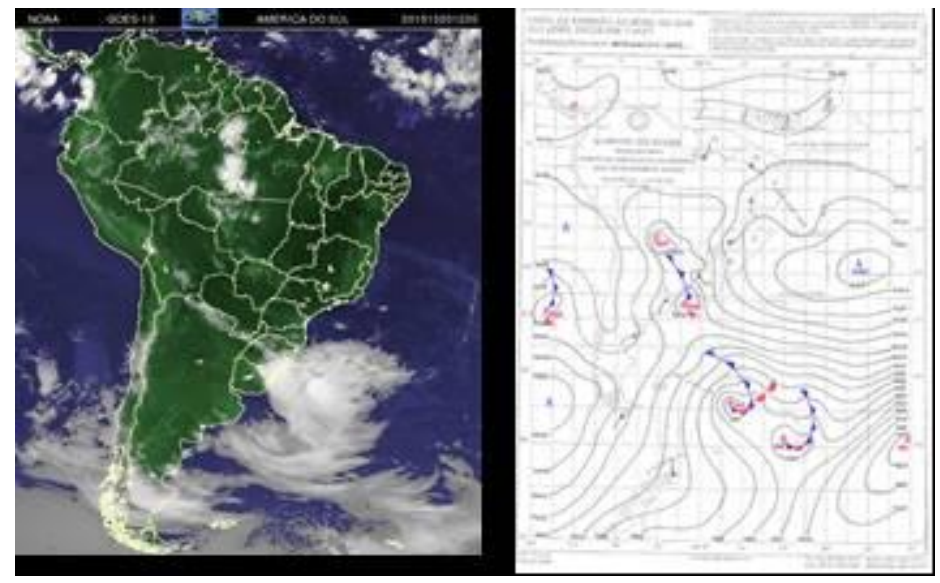

Figura 3: Imagens do satélite e carta sinótica mostrando a atuação das massas de ar em 20/10/2015. Fonte:

CPTEC/INPE e Marinha do Brasil.

Com base nas análises das imagens de satélite e das cartas sinóticas foi identificado o predomínio da massa Tropical Continental entre os dias 15 e 21, período em que foram registrados os mais elevados valores de temperatura do ar no mês. Durante este período, a Alta Subtropical do Atlântico Sul (ASAS) encontrava-se a oeste do continente (INPE, 2016). Durante o mês de outubro, as chuvas foram mais acentuadas na Região Sul do Brasil, como esperado em anos de El Niño. A escassez de chuva na maior parte do Brasil resultou em elevadas temperaturas e baixos valores de umidade relativa do ar (INFOCLIMA, 2016).

Após a análise dos episódios atmosféricos ocorridos no período, o dia 20 de outubro foi tomado como dia de referência para o estudo, quando a temperatura do ar atingiu o valor de $36,6^{\circ} \mathrm{C}$, superando a temperatura máxima absoluta para o mês de outubro registrado em 1963 com valor de $36,4^{\circ} \mathrm{C}$, obtida das Normais Climatológicas para São Carlos de 1961 - 1990. Além dos elevados valores de temperatura do ar, o dia típico experimental apresentou céu limpo com valores de radiação solar global máxima atingindo $880 \mathrm{~W} / \mathrm{m}^{2}$ às $12 \mathrm{~h} 00$, apresentando uma parábola característica de dias sem nebulosidade. As Figura 4 e 5 apresentam a variação dos valores da temperatura do ar e da radiação solar global registrados no dia 20 de outubro. 


\section{OS DESAFIOS DA GEOGRAFIA FÍSICA NA FRONTEIRA DO CONHECIMENTO \\ Instituto de Geociências - Unicamp \\ Campinas - SP \\ 28 de Junho à 02 de Julho de 2017}

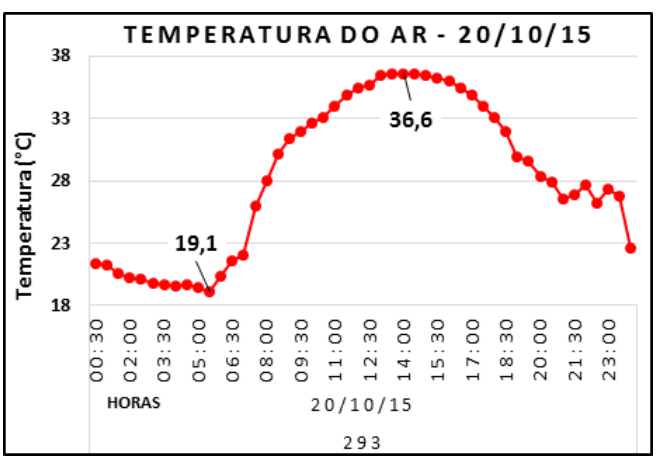

Figura 4: Gráfico da variação da temperatura do ar e da radiação solar no dia 20 de outubro. Fonte: Os autores.

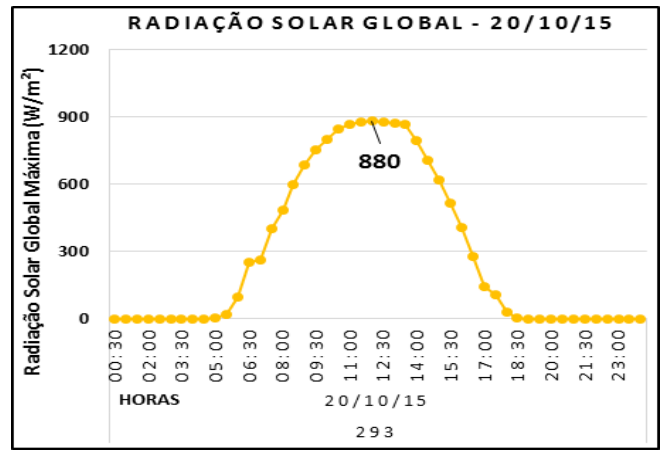

Figura 5: Gráfico da radiação solar global máxima no dia 20 de outubro. Fonte: Os autores.

\subsection{Análise dos dados das plataformas verde e controle}

Para a análise do comportamento térmico dos sistemas de cobertura os valores obtidos foram plotados na forma de gráficos mostrando a variação da temperatura do ar, das temperaturas superficiais superior e inferior do substrato e dos sensores externos das plataformas verde e controle. As Figuras 6 e 7 e a Tabela I mostram as temperaturas referentes ao dia experimental de 20 de outubro.

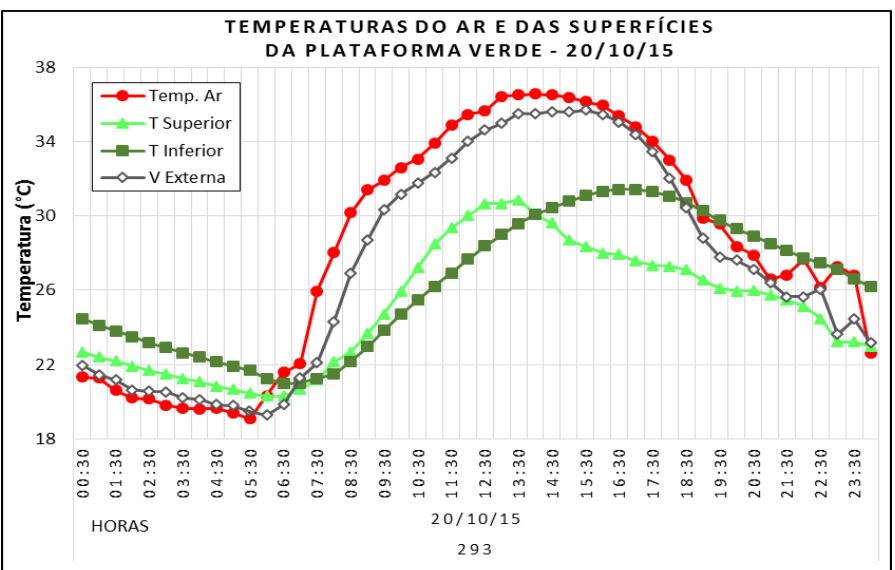

Figura 6: Gráficos dos valores das temperaturas do ar, das superfícies superior e inferior do substrato e da superfície externa da plataforma verde no dia 20 de outubro. Fonte: Os autores. 


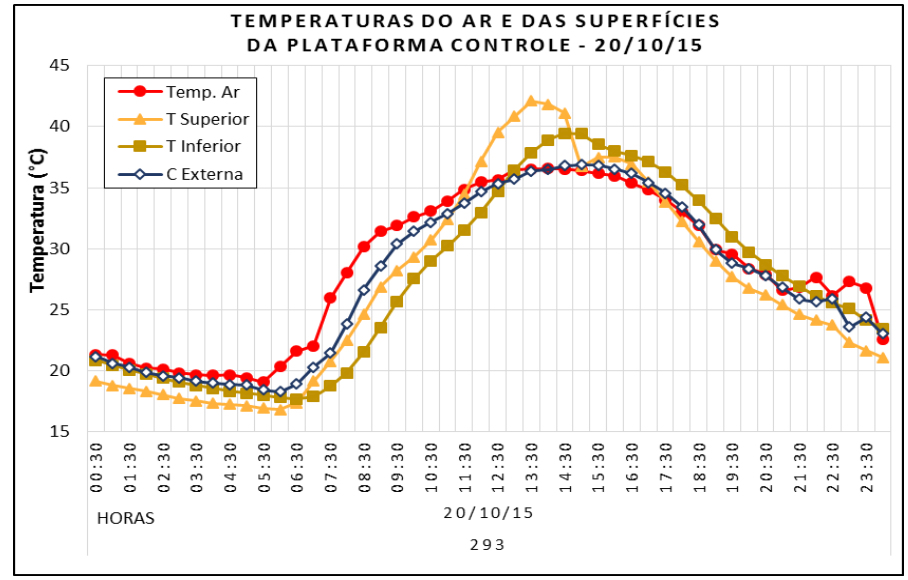

Figura 7: Gráficos dos valores das temperaturas do ar, das superfícies superior e inferior do substrato e da superfície externa da plataforma controle no dia 20 de outubro. Fonte: Os autores.

Tabela I: Valores e respectivos horários da temperatura máxima, mínima e a amplitude térmica do ar, das superfícies superiores e inferiores e dos sensores externos das plataformas verde e controle no dia 20 de outubro.

\begin{tabular}{c|c|c|c|c|c|c|c}
\hline Indicadores & $\mathbf{A r}$ & $\boldsymbol{\theta V S}$ & $\boldsymbol{\theta V I}$ & $\boldsymbol{\theta V} \mathbf{E x t}$ & $\boldsymbol{\theta C S}$ & $\boldsymbol{\theta C I}$ & $\boldsymbol{\theta C}$ Ext \\
\hline Máx $\left({ }^{\circ} \mathbf{C}\right)$ & 36,6 & 30,9 & 31,4 & 35,7 & 42,1 & 39,4 & 36,8 \\
(hora) & $(14 \mathrm{~h} 30)$ & $(13 \mathrm{~h} 30)$ & $(16 \mathrm{~h} 30)$ & $(15 \mathrm{~h} 30)$ & $(13 \mathrm{~h} 30)$ & $(15 \mathrm{~h} 00)$ & $(15 \mathrm{~h} 30)$ \\
\hline Mín $\left({ }^{\circ} \mathbf{C}\right)$ & 19,1 & 20,3 & 21,0 & 19,3 & 16,8 & 17,7 & 18,3 \\
(hora) & $(5 \mathrm{~h} 30)$ & $(6 \mathrm{~h} 00)$ & $(7 \mathrm{~h} 00)$ & $(6 \mathrm{~h} 00)$ & $(6 \mathrm{~h} 00)$ & $(6 \mathrm{~h} 30)$ & $(6 \mathrm{~h} 00)$ \\
\hline$\Delta \mathbf{T}\left({ }^{\circ} \mathbf{C}\right)$ & 17,5 & 10,6 & 10,4 & 16,4 & 25,3 & 21,7 & 18,5 \\
\hline
\end{tabular}

No dia experimental os valores da temperatura máxima das superfícies superiores de ambas as plataformas foram registrados $1 \mathrm{~h} 00$ antes da temperatura máxima do ar. Na cobertura verde o valor da temperatura máxima da superfície inferior foi registrada 3 h00 após o registro da temperatura máxima da superfície superior, superando-a em apenas $0,5^{\circ} \mathrm{C}$. Nas superfícies superior e inferior foram registrados valores de temperatura máxima de $5,7^{\circ} \mathrm{C}$ e $5,2^{\circ} \mathrm{C}$ abaixo da temperatura máxima do ar respectivamente, sendo que a amplitude térmica da superfície superior foi maior do que a da superfície inferior em apenas $0,2^{\circ} \mathrm{C}$.

Na cobertura controle a temperatura máxima da superfície inferior foi registrada 1 h30 após o registro da temperatura máxima da superfície superior e com valor de $2,7^{\circ} \mathrm{C}$ menor. Os valores das temperaturas máximas da superfície superior e inferior da cobertura superaram a temperatura máxima do ar em $7,2^{\circ} \mathrm{C} \mathrm{e}$ $4,4^{\circ} \mathrm{C}$ respectivamente e amplitude térmica da superfície superior foi $3,7^{\circ} \mathrm{C}$ maior do que a dos valores da superfície inferior.

Os sensores das superfícies externas de ambas as plataformas registraram temperaturas máximas no mesmo horário com um atraso térmico de 1 h00 em relação à temperatura máxima do ar, quando o sensor da plataforma verde registrou uma temperatura $0,9^{\circ} \mathrm{C}$ abaixo da temperatura do ar e o sensor da plataforma controle $0,2^{\circ} \mathrm{C}$ acima da temperatura do ar. $\mathrm{O}$ sensor da plataforma verde apresentou uma amplitude térmica $2,1^{\circ} \mathrm{C}$ menor do que o sensor da plataforma controle. 
$\mathrm{Na}$ cobertura da plataforma verde observa-se que no horário em que a temperatura da superfície inferior atinge o seu valor máximo, às 16h30, a temperatura da superfície superior já se encontrava abaixo deste valor, tendo atingido seu valor máximo anteriormente e a temperatura da superfície externa da plataforma estava maior do que a da superfície inferior.

Analisando a variação da temperatura da superfície externa das duas plataformas, os valores registrados na plataforma verde permaneceram abaixo da temperatura máxima do ar. Na plataforma controle a temperatura externa supera a temperatura do ar entre $14 \mathrm{~h} 30$ e $18 \mathrm{~h} 00$ com diferença máxima de $0,8^{\circ} \mathrm{C}$ às 16h30. A Figura 8 mostra a variação das temperaturas da superfície externa das plataformas no dia experimental.

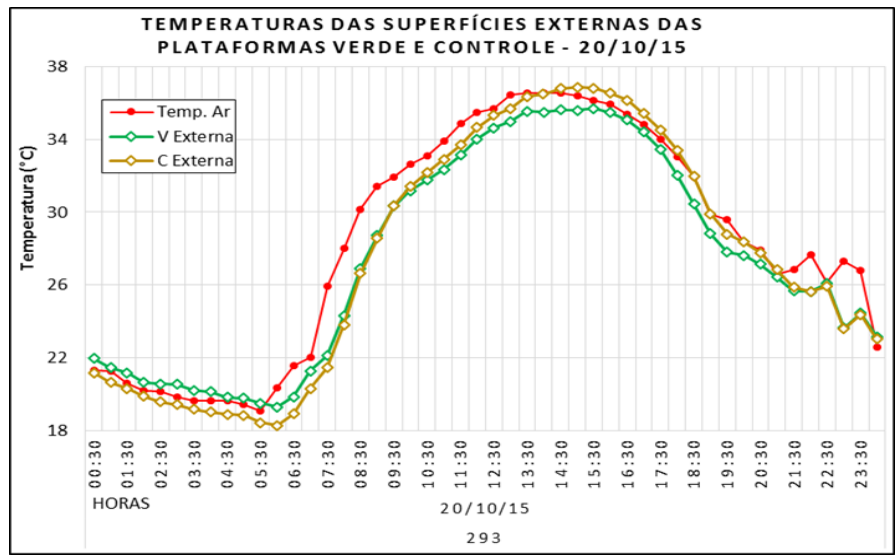

Figura 8: Gráficos dos valores das temperaturas do ar e da superfície externa das plataformas verde e controle no dia 20 de outubro. Fonte: Os autores.

Pode-se perceber que no dia experimental as temperaturas externas acompanham as tendências das respectivas coberturas, onde, na plataforma verde a temperatura máxima da superfície externa não supera a temperatura máxima do ar e na plataforma controle a temperatura máxima da superfície externa supera a temperatura máxima do ar.

A radiação solar é o principal fator que determina a transferência de calor a partir da superfície superior para dentro das camadas inferiores do substrato pela termoconversão resultando no aumento da temperatura destas superfícies durante o período diurno e também na diminuição das suas temperaturas pela perda da energia térmica acumulada para a atmosfera quando cessa a incidência pela presença de nebulosidade e durante o período noturno. Essa amplitude térmica foi menor nas duas superfícies da plataforma verde do que na plataforma controle, assim como foi menor também a diferença entre as temperaturas máximas das duas superfícies na cobertura verde. 
Ressalta-se que o melhor desempenho pela cobertura verde na redução da temperatura nas superfícies do substrato comparado com a cobertura sem vegetação ocorre tanto pelo efeito da evapotranspiração quanto pelo maior albedo dessa cobertura. O sombreamento proporcionado pela camada foliar da vegetação favorece a retenção da umidade no substrato, que perde energia térmica através da evapotranspiração. Na ausência de uma cobertura vegetal, o substrato exposto retém menos umidade que seria evaporada durante o dia e também absorve mais radiação por ser mais escuro do que a camada foliar. Para a obtenção de um melhor desempenho térmico em uma cobertura verde torna-se importante a escolha do tipo de vegetação a ser utilizada, que deve priorizar espécies com maior cobertura foliar e com maior taxa de transpiração.

\section{Conclusões}

O maior atraso térmico e a menor amplitude térmica registrada na cobertura verde em comparação com a registrada nas superfícies da cobertura controle resulta do bloqueio de parte da radiação solar pela vegetação, que tanto impede o ganho de energia térmica pelas camadas inferiores durante o período diurno como também impede que parte desta energia seja perdida para o ambiente.

Desta forma foi possível definir para um dia quente e seco que a cobertura do substrato com uma camada densa de vegetação influencia os processos de troca de calor no perfil do substrato pelo bloqueio de parte da radiação solar incidente, fator principal que determina esses processos, permitindo que a superfície superior não atinja temperaturas acima da temperatura máxima do ar diária e também que esta temperatura se manifeste com maior atraso na superfície inferior que, em última análise, é a que estará em contato com um elemento construtivo, como uma laje ou um forro.

\section{Bibliografia consultada}

BAPTISTA, C. R. W.; MORETINI, C. A.; MARTINEZ, J. L. Arachis pintoi, palatabilidade, crescimento e valor nutricional frente ao pastoreio de eqüinos adultos. Rev. Acad., Curitiba, v. 5, n. 4, p. 353-357, 2007.

COSTA, E.C.C. Arquitetura ecológica: condicionamento térmico natural. São Paulo: Edgard Blücher. p.264, 1982.

CUNHA, D. G. F.; VECCHIA, F. As abordagens clássica e dinâmica de clima: uma revisão bibliográfica aplicada ao tema da compreensão da realidade climática. Ciência e Natura, UFSM, 29 (1): 137-149, 2007.

DURHMAN, A. K.; ROWE, D. B.; RUGH, C.L. Effect of Substrate Depth on Initial Growth, Coverage, and Survival of 25 Succulent Green Roof Plant Taxa. HortScience v. 42, n. 3, p.588-595, 2007.

FREITAS, R. O que é conforto. In: Encontro Nacional Sobre Conforto No Ambiente Construído, 8; Encontro Latino-Americano Sobre Conforto Ambiente Construído, 4, 2005, Maceió. Anais.Maceio: COTEDI, p. 726-735, 2005.

INFOCLIMA - Boletim De Informações Climáticas do CPTEC/INPE, Ano 22, Número 11, 2015. Disponível em: < http://infoclima1.cptec.inpe.br/ > Acesso em: 12/01/2016.

INPE - Instituto Nacional De Pesquisas Espaciais. Análise Sinótica. Disponível em: < http://www.cptec.inpe.br > Acesso em: 12/01/2016. 
MONTEIRO, C. A. F. A frente polar atlântica e as chuvas de inverno na fachada Sul Oriental do Brasil: estudo geográfico sob forma de atlas. São Paulo: Instituto de Geografia- USP, 1969.

MONTEIRO, C. A. F. A dinâmica climática e as chuvas no Estado de São Paulo: estudo geográfico sobre a forma de atlas. São Paulo: Instituto de Geografia- USP, 1973.

NIACHOU, A.; PAPAKONSTANTINOU, K.; SANTAMOURIS, M.;TSANGRASSOULIS, A.; MIHALAKAKOU, G. Analysis of the green roof thermal properties and investigation of its energy performance. Energy and Buildings 33, 719-729, 2001.

OKE, T.R.. Boundary Layer Climates. 2nd ed. New York:Methuen. 1987

PEEL, M. C.; FINLAYSON, B. L.; MCMAHON, T. A. Updated world map of the Köppen-Geiger climate classification. Hydrology and Earth System Sciences. No. 11, p. 1633-1644, 2007.

SEIXAS, G. T. C. Climatologia aplicada à Arquitetura: investigação experimental sobre a distribuição de temperaturas internas em duas células de teste. 2015. 126p. Tese (Doutorado) - Escola de Engenharia de São Carlos da Universidade de São Paulo, São Carlos, 2015.

SERRA, R. Arquitectura y climas. Barcelona: Gustavo Gili S.A. p.94, 2002.

SUSCA, T., GAFFIN, S. R. e DELL'OSSO, G. R. Positive effects of vegetation: urban heat island and green roofs. Environ Pollut. Vol. 159, n. ${ }^{\circ}$ 8-9, p. 2119-26, 2011.

VECCHIA, F. A. S. Clima e ambiente construído: a abordagem dinâmica aplicada ao conforto humano. Tese (Doutorado) Faculdade de Filosofia Letras e Ciências Humanas, Universidade de São Paulo, São Paulo, 1997.

YOK, T. P.; SIA, A. A Selection of Plants for Green Roofs in Singapore. Publication of National Parks Board, Singapore, 2008.

YOUNG, H.D.; FREEDMAN, R.A. Física II: Termodinâmica e Ondas. 12a ed. São Paulo, AddisonWesley, 2008. 